\title{
Editorial: Politics in 2013 - The Changing Landscape of Academic Publishing
}

Over the course of our first year editing Politics academic publishing has faced increased scrutiny from both inside and outside the academy. The so-called 'Academic Spring' singled out access to, and management of, academic journals for particular attention. We believe responding to both challenges is important for Politics and wanted to take the opportunity of this annual editorial statement to reflect on the journal's strategy with regard to both.

To take the latter first, peer review, editorial decision making and acceptance rates have been the target of much comment. We believe that better access to information about journal management is important to colleagues at all career stages and aim to outline some important elements of Politics review and publication strategy below. At the same time, we also have some strong reservations about how journal data is being interpreted in some quarters. Indeed, some of the assumptions about editing journals and the purpose of peer review that underpin these interpretations are based on misperceptions. In particular, the focus on turnaround times for peer review often fails to acknowledge that this process is an essential component for improving work that has been submitted for publication. Recognising this important function, the standard guidance we give our referees now stresses the developmental role that the peer review process should play. Even if a paper is not accepted by Politics, we aim to provide the author with feedback that will improve it. As helpful feedback requires considerable time - to write reviews, consider decisions and draft helpful letters - from referees and editors, it is in no one's interest to rush this process. It is worth noting that reviewers (like editors) are not paid for this work. We are extremely grateful, therefore, to our referees for the time and expertise they give to Politics.

\section{Peer review at Politics}

The editorial team at Politics is comprised of two editors and three associate editors. Every submission is read by at least one editor before an initial decision whether to send it out for peer review is made. If an editor determines that a piece should not be sent out for review, this decision is then normally reviewed by a second member of the editorial team. If this decision is confirmed, the author is contacted as quickly as possible with a letter that includes an explanation of why the paper was not sent out for review and measures that could be taken to improve the paper. In some cases, a resubmission may be invited if the editors feel that the paper has potential. In 2012, desk rejections were turned around on average within 7 working days, while $67 \%$ of submissions received were sent out for review. 
In our experience, there are two major reasons why papers are rejected in the initial screening process. Firstly, some submissions are found to be unsuitable for the journal because, in our judgement, they are too narrow to resonate with our audience. Our vision is for Politics to publish timely, research-led reflections on the state of the art, the state of the world, and the state of disciplinary pedagogy. As a part of this vision, Politics remains steadfastly pluralist with regards to approaches, theories, methods, and empirical foci. While one cannot expect that every article in every issue of Politics will appeal to every reader, we believe that every article should be able to communicate the wider significance of its research problem and importance of its conclusions to all readers. Exercising our editorial judgment at an initial stage helps to ensure that Politics retains its broad audience in politics and international studies. Secondly, in other cases it is our judgement that submissions are still too under-developed to be sent out for peer review. Rejecting these articles at an initial stage removes from the reviewing pool papers whose current states of under-development make it highly unlikely that they will be positively reviewed. We believe this has two virtues: on the one hand it means authors have a constructive, not negative, encounter with the editorial process despite their paper being underdeveloped; on the other, it allows peer reviewers to focus on papers that have a realistic chance of publication.

All papers that pass through the initial editorial review are then assigned to associate editors who guide them through the peer review process. Associate editors select referees, contact referees, follow-up with referees, interpret the guidance offered by the referee reports, and make an initial decision as to whether a paper will be accepted, asked to revise and resubmit, or rejected. In some cases, decisions are straight forward as the referees unanimously agree on the merits of a paper. In most cases, the views of referees can be quite varied. Thus, associate editors have to make difficult decisions about whether a paper should be published (with or without revisions). In navigating referees' reports, associate editors are guided by disciplinary expectations of academic rigour, the aims of the journal, the determination to make every submission stronger, and the principle that work that is of a publishable standard ought to be published.

We aim to make initial decisions on the basis of 3 referees' reports. Once an initial decision has been made by an associate editor, the original paper, referees reports, the associate editor's report, and the initial decision are then reviewed by an editor to ensure consistency in standards and fairness. In cases of differing opinion, the second editor is brought in to reach a decision. In 2012, $21 \%$ of articles submitted were accepted. The mean turnaround time for initial decisions for papers that underwent peer review was 42 working days. If a paper is accepted, it is likely that publication will be conditional on the successful completion of revisions. Periodically, decisions made at all stages and the rationales for these decisions are reviewed by the entire editorial team to ensure that consistency in standards and outcomes is being achieved.

We believe that Politics offers a fair and rigorous peer review process that plays an important role in developing research papers into publishable articles. Every article reviewed by Politics is read by at least two members of the editorial team in addition to referees. While our current turnaround times place the journal 
amongst the swiftest in the discipline, we place more importance on - and will thus prioritise - the feedback that we are able to offer those who choose to submit their work to us. Research from all colleagues, regardless of career stage, can always benefit from the close readings and constructive criticism provided by the peer review process. This does not mean that all authors and referees always agree with our final decisions. However, we are confident that decisions are reached through careful deliberation based on the opinions of leading experts. And these deliberations take place within a structure that is designed to promote consistency, fairness and rigor. This overview of the review process at Politics should highlight that the common misperception that editorial decision making is capricious or formulaic and that managing a journal takes little time or effort, does not capture the reality of editing a journal. The review process requires a considerable investment of time and the careful exercise of judgement in order that it has positive benefits for the authors involved.

We will continue to look for ways to make the peer review process more efficient and to improve the feedback that authors receive on their work. But there is only so much we can do on our own. For colleagues who are interested in improving the overall quality of peer review in the profession, we offer several suggestions;

1. As a rule of thumb, be prepared to peer review at least three items for each paper, book chapter, book, or research proposal that you have submitted for review in the previous twelve months. Promote this as a professional norm.

2. If you are contacted to peer review an article, let an editor know as quickly as possible whether you are able to provide a report. Editors understand that potential peer reviewers may not be able to referee every time that they are contacted. But the sooner editors know either way, the sooner they can move forward with certainty.

3. When reviewing, it is really important to provide a report that is both helpful to the authors of the paper you are reading as well as to the editors. With excellent resources available online from other journal editors, we do not want to re-invent the wheel by repeating the same advice. ${ }^{1}$ The most important things are to provide a clear and fair evaluation of whether the paper is currently of a publishable standard, to communicate what could be done to improve the paper, and to do so in a way that is honest but constructive.

\section{The Finch Report and Open Access}

The second major development in the academic publishing landscape over the past year has been the recommendations arising from the Finch Report. At the present time, it is unclear what direct impacts mandatory open access for all publicly funded research in the UK will have on the discipline of political and international studies. However, it is important to note that the terms of Politics current licensing agreement allow all authors to post a pre-acceptance version of their article to any online repository at any time (including during the peer review process) subject to several minor conditions regarding attribution. 24 months after publication, authors may post a post-acceptance version-though not the Wiley Blackwell PDF-again subject to adhering to minor conditions. In order to maximise the exposure of their articles 
we strongly encourage all of our authors to make use of these licensing provisions and to post drafts to online repositories like SSRN (http://www.ssrn.com/).

As the implications of the Finch Report become clearer, we will work closely with the Political Studies Association and other PSA journal editors in efforts to mitigate any negative impacts-particularly for postgraduates, early career researchers, independent scholars, and colleagues who are employed on part-time or temporary contracts-that may arise from the mooted 'gold model' of open access. ${ }^{2}$ Similarly, we will want to ensure that any changes that become necessary do not negatively impact upon Politics' ability to attract the very best research from around the world.

\section{Looking forward}

While much has been accomplished in the past year, we still feel that there is more to be done. Primarily, we believe that we need to continue to work on elevating the profile of Politics. This coming year, our focus will be on improving the journal's permanent online presence. We are currently in the process of developing a Politics blog that will serve as the public entry portal for the journal. In the future authors of articles accepted for publication in Politics will be asked to provide a blog post of 250-500 words that explains a key aspect of their published work in accessible language. One motivation is certainly academic impact. For example, research from the World Bank has shown that 'a link on a popular blog results in a substantial increase in abstract views and downloads' (McKenzie and Özler, 2011, 29). But our ambitions for impact go beyond academia. We believe that providing a platform for showcasing the work of our authors in an accessible form will make a positive contribution to the profile of the discipline amongst school students, teachers, media, and the wider public. In addition to maximising the audience for our authors this strategy matches our editorial belief that the discipline of politics and international studies has a prominent role to play in fostering informed discussions of the key political challenges of our time and the normative possibilities offered by political engagement.

\section{Notes}

1 We recommend a blog post called 'The Editors Speak: What Makes a Good Review', a collection of opinion from the editors of eleven social science journals. Available at http:// orgtheory.wordpress.com/2011/05/31/the-editors-speak-what-makes-a-good-review/. It is worth noting the comments about the correlation between length of review and its constructive benefits for editors and authors. It is our experience that constructive reports are a minimum of 2 paragraphs, but often stretch to 2 pages. We realise this is a significant investment of time on the part of our reviewers and would like to extend out thanks once again to all those that have reviewed for us in the past year.

2 The so-called 'gold model' of open access requires authors to pay publishers article publication charges. The so-called 'green model' of open access offers authors the opportunity to post final published versions of articles to online repositories and personal websites (See Harnad et al., 2004)

\section{References}

Harnad, S. et al. (2004), The green and the gold roads to Open Access [online] Nature Web Focus. Available from: http://www.nature.com/nature/focus/accessdebate/21.html [Accessed 8 October, 2012]

McKenzie, D. and Özler, B. (2011), 'The Impact of Economics Blogs', World Bank Policy Research Working Paper 5783 [online] Available from: http://www-wds.worldbank.org/servlet/WDSContentServer/ WDSP/IB/2011/08/29/000158349_20110829130036/Rendered/PDF/WPS5783.pdf [Accessed 8 October, 2012] 